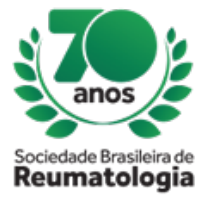

\title{
SYSTEMIC ERYTHEMATOSUS LUPUS TRIGGERED BY AN ILIOPSOAS ABSCESS DUE TO TUBERCULOSIS
}

Elisa Fernandes de Melo (Universidade de Taubaté, Taubaté, SP, Brasil), Raylane Shellyda de Almeida Anate (Universidade de Taubaté, Taubaté, SP, Brasil), Vinicius Verlangieri Soubihe (Universidade de Taubaté, Taubaté, SP, Brasil), Natália Engler Ravasio (Universidade de Taubaté, Taubaté, SP, Brasil), Amauri Marcelo Cisotto Rocha Junior (Universidade de Taubaté, Taubaté, SP, Brasil), Paulo Giovanni Estevam (Universidade de Taubaté, Taubaté, SP, Brasil), Daniel Renato Gonçalves Duarte (Universidade de Taubaté, Taubaté, SP, Brasil), Glenda Alves Pereira de Oliveira (Universidade de Taubaté, Taubaté, SP, Brasil)

\section{BACKGROUND}

Iliopsoas muscle abscess (IPA) is an uncommon disease that predominantly affects young adults. Recently there was an increase in the prevalence of disease, being related to immunodeficiency. The abscess can be classified according to the pathogenic mechanism, in primary and secondary. In the primary form, it originates from hematogenous dissemination, facilitated by an underlying immunosuppression. The secondary form involves the dissemination by contiguity of adjacent structures infected. The main etiological agent is Staphylococcus aureus (88\%), followed by Streptococcus spp (5\%) and Escherichia coli.

\section{CASE REPORT}

Female, 41 years of age, reports that in June 2018 presented with a vespertin fever associated with pain in the left leg that worsened during ambulation or flexion. Previous history of Pyoderma Gangrenosum over 2 years ago with the presence of a cribriform scar. Laboratory test showed anemia with positive direct Coombs, leukocytosis $(29,700)$ without left shift, alteration of inflammatory markers (CRP 22.9 and ESR 96), a thin dotted nuclear standard ANA with a title of $1 / 80$, positive RF, positive lupus anticoagulant antibody, lower level of complement components (C3 and C4) and negative tumor markers (CA-125 and CA 19.9). Transthoracic echocardiogram was performed demonstrating a preserved ejection fraction and laminar pericardial effusion. Patient also underwent a pelvis x-ray showing an irregularity of the iliac contours with a radio-opaque image adjacent to the left acetabulum, which on CT (figure 1) and MRI was an expansive nodular formation with heterogeneous density located in the left annexial region, 51x50 $\mathrm{mm}$, and a heterogeneous thickening of the distal portion of the left psoas, iliopsoas and internal oblique muscles. The abscess was drained and the cultures performed were negative. Specific treatment for SLE was initiated with significant clinical improvement. After 60 days of incubation, Mycobacterium tuberculosis was isolated and initiated RIPE scheme for 9 months with good response.

\section{CONCLUSION}

Although S. aureus is the most common agent in this type of abscess, in countries where tuberculosis is endemic, Mycobacterium tuberculosis is a highly observed infectious agent. However, the occurrence of abscess in the psoas muscle as the main presentation of tuberculosis, without any active infectious focus elsewhere, has been poorly documented. As an uncommon presentation of extrapulmonary tuberculosis, there is usually a delay in its diagnosis within 45 days due to the non-specificity of the condition. As in the case described, the diagnosis of tuberculosis was only performed after the results of the material culture. 